\title{
REVISTAMATĒRIA
}

ISSN 1517-7076 artigo 11769, pp.1094-1104, 2016

\section{Estudo dos parâmetros de estampagem incremental para PVC}

\author{
Study of incremental sheet forming \\ process of PVC
}

Marcelo Pinto Pradella ${ }^{1}$, Luis Fernando Folle ${ }^{1}$

\footnotetext{
${ }^{1}$ Mestrado em Design Uniritter - UniRitter - Porto Alegre - RS

e-mail: marcelopradella@hotmail.com; luis_folle@uniritter.edu.br
}

\begin{abstract}
RESUMO
Na Engenharia de Fabricação, existem diversas áreas de conhecimento voltadas ao estudo dos processos de fabricação que dão origem aos produtos fornecidos para as indústrias de transformação e produtos destinados aos consumidores finais que podem ser processados a partir de chapas, fios, barras e perfis. Em ambos os casos, um dos processos de fabricação mais usado é a "Conformação Mecânica" que é o processo mecânico onde se obtém peças através da compressão de metais sólidos em moldes, utilizando a deformação plástica da matéria-prima para o preenchimento das cavidades dos moldes. No entanto, existe um processo que pode fazer isso sem a necessidade de moldes, a chamada 'Estampagem Incremental' que consiste em desenhar o formato da peça em uma fresadora $\mathrm{CNC}$ através de um punção cilíndrico com ponta arredondada. $\mathrm{O}$ objetivo do presente artigo é fazer um estudo sobre o processo de Estampagem Incremental de polímeros como sendo um novo tipo de tecnologia de Prototipagem Rápida que é baseada no processo de conformação de material, diferente dos processos já existentes de remoção ou adição de material. Os testes foram feitos em uma geometria em formato de tronco de pirâmide, em três estágios subsequentes e o objetivo é avaliar alguns parâmetros como a temperatura de trabalho e o diâmetro do punção no resultado final do protótipo. O material escolhido para o estudo foi o PVC pois esse está presente em muitos estudos já feitos sobre o assunto. Testes práticos com PVC indicaram que uma variação na temperatura de trabalho do material de $20^{\circ} \mathrm{C}$ resultou em um aumento significativo nos resultados de deformação quando feito os testes.
\end{abstract}

Palavras-chave: Prototipagem Rápida, Estampagem Incremental de Polímeros, PVC, Tecnologia aplicada ao Design.

\begin{abstract}
In Manufacturing Engineering, there are several areas of knowledge focused on the study of manufacturing processes that give rise to products supplied to the processing industries and products to final consumers that can be processed from sheet, wires, rods and beams. In both cases, one of the most widely used manufacturing processes is the "Metal Forming" which is the mechanical process that pieces can be obtained by compression of solid metal in molds using plastic deformation of the material for filling the molds cavities. However, there is a process that can do the same without the need for molds, the so-called incremental sheet forming which consists of drawing the workpiece on a CNC form milling using a small cylindrical punch with a rounded tip. The purpose of this work is to make a study of the process of incremental sheet forming of polymers as a new type of rapid prototyping technology that is based on the process of forming material, different from the existing processes for removing or adding material. The tests were done in a geometry pyramid trunk format, in three subsequent stages and the objective is to evaluate some parameters such as temperature of working and the punch diameter in the final result of the prototype. The material chosen for the study was the PVC because that is present in many studies already done on the subject. Tests made with PVC indicated that a variation in $20^{\circ} \mathrm{C}$ of material working temperature resulted in a significant increase in forming results during the tests.
\end{abstract}

Keywords: Rapid Prototyping, Incremental Sheet Forming of Polymer, PVC, Technology Applied to Design. 


\section{INTRODUÇÃO}

Nos últimos anos, a abertura de mercados locais para a competição mundial tem levado a uma mudança fundamental no desenvolvimento de novos produtos. A fim de permanecerem competitivos, os fabricantes devem ser capazes de alcançar e sustentar a si mesmos no mercado mundial. Os fabricantes devem ser capazes de fornecer produtos para cumprir a satisfação total dos clientes, mantendo alta qualidade com tempo de entrega curto a custos razoáveis, sem deixar de se preocupar com o meio ambiente e cumprir todos os requisitos de segurança.

Em muitas áreas, há grande incerteza se um novo projeto vai realmente cumprir o que é desejado. Os projetos novos, muitas vezes têm problemas inesperados. Protótipos são frequentemente utilizados como parte do processo de design de produto para permitir que engenheiros e designers tenham a capacidade de explorar alternativas de projeto, fazer testes e confirmar o desempenho antes da produção de um novo produto. Nesse sentido, os protótipos servem para adaptar as incógnitas específicas ainda presentes no desenho pretendido. No entanto, existem diversas formas de se obter um protótipo e isso é estudado por um ramo da produção automatizada chamada de "Prototipagem Rápida (PR)".

Dentre os grandes grupos de Prototipagem Rápida destacam-se à aditiva e à subtrativa. As duas tecnologias têm limitações, a subtrativa pode gerar grande desperdício de material e a aditiva é usada apenas com materiais aos quais a tecnologia foi projetada, não sendo usada, por vezes, para materiais de interesse da indústria. Existe, no entanto, um novo grupo que está sendo estudado para aplicações industriais, chamada de "Estampagem Incremental (EI)" que é baseada em um processo de fabricação de mesmo nome. Essas tecnologias formariam um terceiro grupo de PR, chamada de "Conformação de Material" ou também chamada de tecnologias formativas.

Alguns estudos já foram desenvolvidos nessa área. MARTINS et al [1] estudou esse processo para cinco diferentes polímeros, Polioximetileno (POM), polietileno (PE), poliamida (PA), policloreto de vinila (PVC) e policarbonato (PC). Todos esses polímeros facilmente utilizados em produtos comerciais. Na pesquisa de MARTINS et al [1], foi constatado que cada material apresenta um tipo de falha característica que induziu a um limite que cada material pode ser conformado. Posteriormente outros dois trabalhos foram publicados sobre o mesmo assunto por FRANZEN et al [2] e SILVA et al [3], porém o material de análise foi o PVC. Nesses trabalhos, o interesse foi aprofundar as análises sobre as possibilidades do uso de EI de PVC para produção de pequenos lotes de produtos com esse material. Mais recentemente, ALKAS YONAN et al [4] fez uma análise através de simulação numérica de um PVC para tentar prever o formato que a peça irá ter ao se aplicar alguns parâmetros específicos, eles constataram que os modelos de descrição de material precisam ser melhorados para que os resultados sejam mais próximos.

DAVARPANAH et al [5] fez um estudo da influência do tamanho do incremento em profundidade e rotação da ferramenta no modo de falha da peça. O material estudado foi o PLA e PVC. BAGUDANCH et al [6] testou vários modelos matemáticos de materiais que poderiam ser utilizados para prever os dados experimentais de amostras de PVC e PC submetidas a um teste uniaxial simples realizada a várias temperaturas e velocidades. BAGUDANCH et al [7] avaliou a influência de alguns parâmetros de processo sobre o consumo energético na estampagem incremental do PC e PVC. Os resultados foram utilizados para identificar a combinação mais adequada dos parâmetros do processo, a fim de minimizar o consumo de energia e os custos. BAGUDANCH et al [8] se concentrou em determinar a influência dos principais parâmetros do processo, isto é, incremento em profundidade, rotação da ferramenta, velocidade linear da ferramenta, diâmetro da ferramenta e espessura da chapa, sobre a força máxima de conformação do material. Os autores também mediram a temperatura que foi gerada pela ferramenta na chapa quando a ferramenta estava com a maior rotação que foi de $74^{\circ} \mathrm{C}$, no entanto, isso foi gerado pelo atrito apenas. Eles também usaram o PVC para os testes.

No presente trabalho serão estudadas algumas variáveis que poderão ajudar na confirmação da tecnologia de Estampagem Incremental como, por exemplo, na prototipagem de embalagem. Os parâmetros de estudo desse trabalho foram o diâmetro do punção (três diâmetros foram analisados), a temperatura utilizada durante o processo (temperatura ambiente e com aquecimento) e a trajetória do punção.

\section{MATERIAIS E MÉTODOS}

A seguir serão descritos os materiais, equipamentos e testes usados para a metodologia adotada.

\subsection{Geometria das peças a serem estampadas}

Para esse experimento, optou-se por escolher um tronco de pirâmide retangular, segundo mostra a Figura 1a, na qual os ângulos foram definidos pelo grau máximo de esforços na estampagem, desde uma conformação 
baixa do material, isto é, com ângulos de parede baixos, até uma estampagem mais severa.

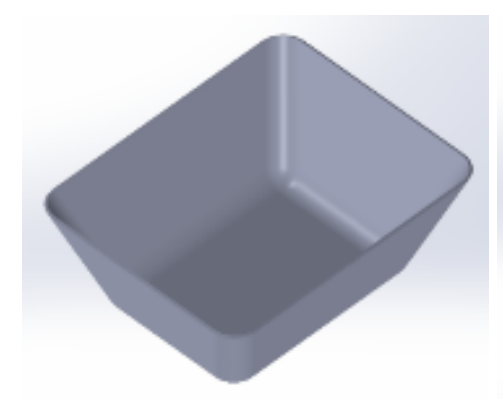

(a)

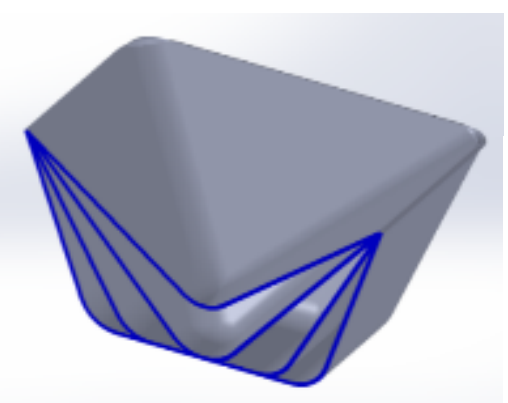

(b)

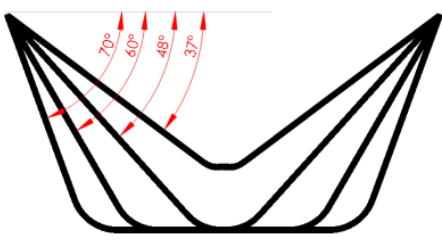

(c)

Figura 1: (a) Formato escolhido para ser testado com EI de polímeros, (b) corte do formato para se visualizar a diferença de cada estágio de conformação, (c): ângulos de parede de cada estágio testado.

Foram analisadas as deformações máximas em cada etapa da estampagem por meio do exame de "visioplasticidade" que consiste em verificar através de aparatos visuais, ou seja, medidos, as deformações que ocorrem na superfície do material trabalhado. Optou-se também, por usar vários estágios de deformação pois o material deve ser trabalhado gradualmente para que se possa saber qual o máximo que esse suporta. Assim, a estampagem, além de incremental, ou seja, em incrementos de deslocamento vertical, apresenta estágios de deformação em etapas distintas. A Figura 1c mostra os ângulos de parede de cada estágio aplicado. A sequência de testes foi do menor para o maior ângulo, ou seja, para se chegar ao ângulo máximo $\left(70^{\circ}\right)$, a chapa antes passou pelos ângulos de $37^{\circ}, 48^{\circ}$ e $60^{\circ}$ em sequência. Os ângulos de parede foram aumentados em sequência pois já foi comprovado através de pesquisas que o material é mais suscetível a falha quanto maior o ângulo de parede [9,10], no entanto, não se sabe com precisão qual é esse ângulo para alguns materiais, como PVC com a espessura usada. Os ângulos foram subdivididos diminuindo cerca de $10^{\circ}$ de um estágio para outro até que se atingisse o valor de $37^{\circ}$ que corresponde a uma geometria em formato de pirâmide completa.

A máquina usada para os testes de estampagem incremental foi um centro de usinagem $\mathrm{CNC}$ (prototipadora), marca Roland modelo DX 650, com o software Modela Player 4. O material de estudo foi uma chapa de PVC de 0,6 mm de espessura. Essa espessura foi determinada, pois a prototipadora não apresenta uma alta capacidade de trabalho em materiais duros, então uma chapa muito espessa poderia sobrecarregar a máquina e inviabilizar os testes.

As ferramentas utilizadas no processo foram fabricadas em aço-ferramenta (aço rápido usado para brocas de fresamento) com ponta arredondada de 1,5 mm, $3 \mathrm{~mm}$ e $6 \mathrm{~mm}$ de diâmetro. Esses diâmetros foram escolhidos para avaliar se a área de contato entre a ferramenta e a chapa tem influência no formato final da peça desejada. A ferramenta desliza sobre a chapa estampada e causa estiramento e deformação. $\mathrm{O}$ arredondamento das ferramentas foram feitos com lixas de 400 de gramatura e polidas com lixa de 1200 .

Como uma das finalidades do trabalho é testar a aplicação de temperatura na chapa para se avaliar se a elevação da temperatura contribui para o formato final da peça, foi utilizada, como fonte de calor, uma lâmpada halógena de $500 \mathrm{~W}$ de potência direcionada para a chapa antes de ser submetida à conformação, como mostra a Figura 2, e permaneceu por cerca de 30 min focada na chapa para que houvesse uma homogeneização da distribuição de temperatura. A temperatura média medida em vários pontos da chapa foi de $55^{\circ} \mathrm{C}$.

A temperatura da chapa, Figura 2, foi medida com a utilização de um Termômetro Digital a Laser Infravermelho, modelo Td962, marca Icel. 


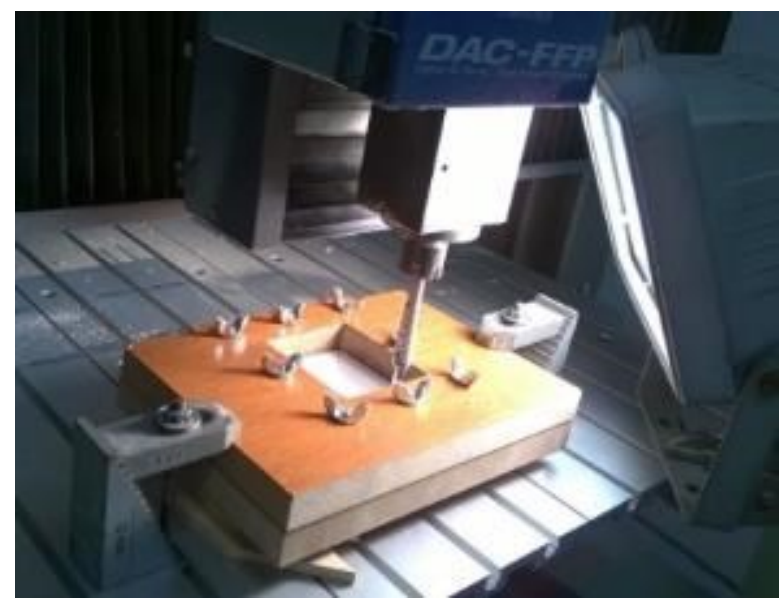

Figura 2: Lâmpada usada no aquecimento das chapas.

\subsection{Parâmetros da El}

A ferramenta de conformação da chapa pode-se deslocar com velocidade controlada através do plano da chapa. Esse parâmetro é introduzido no software Modela Player 4 (exclusivo de operação da máquina) que comanda a essa velocidade. A velocidade de estampagem utilizada nos testes foi de $180 \mathrm{~mm} / \mathrm{min}$. Esse valor foi atribuído para que houvesse uma minimização da influência da velocidade no formato final da peça e que também não gerasse um teste extremamente demorado que poderia durar até 24 horas para se obter uma amostra caso a velocidade fosse muito reduzida.

A profundidade de passe vertical é a distância entre cada passe realizado pela ferramenta na direção do eixo $\mathrm{Z}$ da máquina $\mathrm{CNC}$, ou seja, na direção da profundidade da peça. É um parâmetro que influencia significativamente a moldabilidade da chapa segundo CASTELAN [11]. Cada passe feito na superfície da chapa de PVC (profundidade no eixo Z) tem incremento de $0,1 \mathrm{~mm}(\Delta \mathrm{Z})$. Esse valor foi colocado, de forma semelhante a velocidade, para que fosse o menor possível sem tornar o processo muito demorado.

Nos primeiros testes, optou-se por usar rotação de $3000 \mathrm{rpm}$ na ferramenta que é a rotação mínima que a máquina pode gerar. No entanto, foi abandonado logo no início, pois, verificou-se que, a ferramenta imprimia uma torção no formato da peça à medida que avançava na superfície da chapa. Para isso, a árvore (spindle) da máquina foi desconectada e, por conseguinte a ferramenta ficou livre, proporcionando menor atrito de contato. Com menor atrito entre a ferramenta e a chapa, houve uma diminuição do efeito do torção da peça.

Outro parâmetro definido foi a trajetória da ferramenta. Conforme o tipo de geometria que se quer chegar (produto final), a trajetória seguirá um tipo de estratégia de estampagem incremental. Para tanto, é utilizado um software CAM específico para o tipo de CNC utilizada. No software CAM utilizado, escolhe-se o tipo de estratégia, sendo colocados, à disposição, vários caminhos: linear na direção $\mathrm{X}$, linear na direção $\mathrm{X}$ $+\mathrm{Y}$, circular, etc. Dessa forma, dependendo da geometria do objeto a ser estampado, escolhe-se a melhor estratégia, ou seja, a que gera menor falhas ao processo. A trajetória escolhida foi a de contorno da peça onde a mesma é moldada através da passagem da ferramenta de fora para dentro da peça.

Como os testes foram executados em uma Fresadora, serão descritos alguns parâmetros do software CAM utilizado, Modela Player, modificados para esse tipo de execução. Todos os testes foram feitos em modo finishing, ou seja, módulo de acabamento, mostrado na Figura 3(a). Já na Figura 3(b), os passes verticais foram ampliados para melhor visualização da trajetória da ferramenta. A Figura 3(b) foi gerada exclusivamente para melhorar o entendimento, pois na Figura 3(a) não é possível verificar o formato da trajetória da ferramenta devido ao reduzido passe vertical aplicado. 


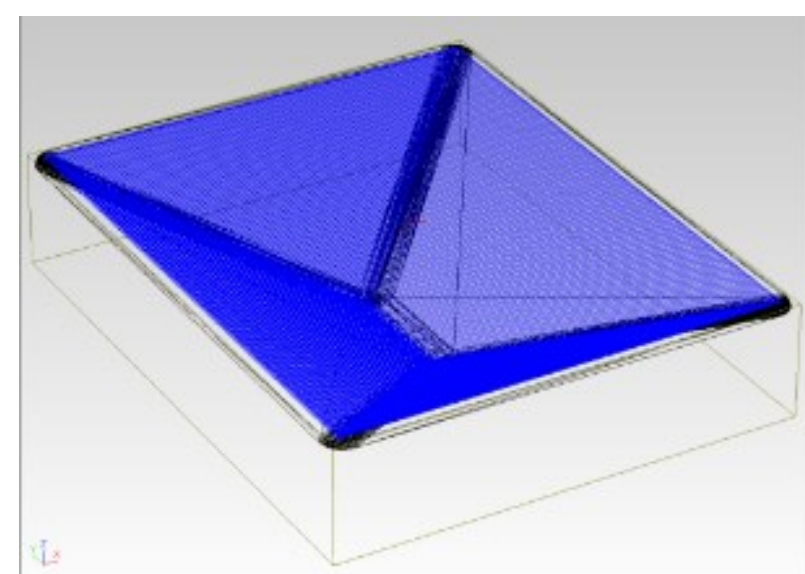

(a)

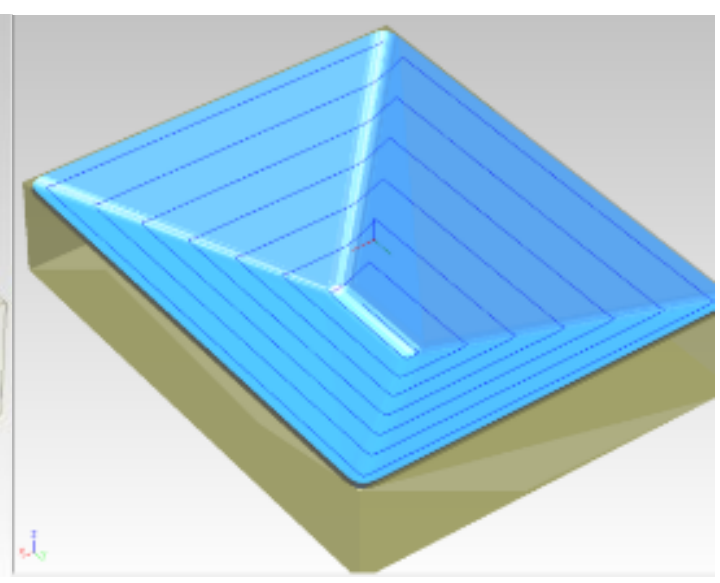

(b)

Figura 3: (a) formato da trajetória do punção (real); (b) formato da trajetória do punção (imagem ampliada).

Todo processo de Estampagem Incremental requer o uso de lubrificante na superfície da chapa pois promove uma redução no atrito entre chapa e ferramenta. Se isso não for feito, a chapa acaba aderindo ("grudando") à ferramenta e promovendo remoção de material, o que deve ser evitado. É um fator adicional, embora necessário, e deve ser levado em conta, independente do tipo de lubrificante. Utilizou-se vaselina sólida industrial, a qual foi aplicada, antes do processo de estampagem, com o auxílio de um pincel macio.

Ainda dentro do software CAM, pode-se determinar o sentido que a CNC irá realizar o incremento no material, ou seja, o sentido horário e o anti-horário. Essa possibilidade se tornou importante durante o experimento, pois essa estratégia fez com que a deformação se prolongasse justamente pela inversão de sentido na execução de cada etapa do processo, ou seja, se na primeira etapa foi utilizado o sentido horário, na segunda é utilizado o anti-horário e assim por diante, prevenindo que a peça seja torcida durante o processo de conformação até o final de todas as etapas.

Para quantificar as deformações da chapa foram utilizadas gravações de uma grade círculos, com diâmetro de $3 \mathrm{~mm}$. Essa técnica já é aplicada para medições em chapas metálicas. A gravação dos círculos de medição na chapa foi feita com a utilização de uma caneta, tipo marcador permanente para plásticos, acrílicos, vidro, vinil, a qual foi fixada ao spindle da CNC por braçadeiras metálicas conforma a Figura 4, onde mostra o momento da gravação na chapa de PVC.

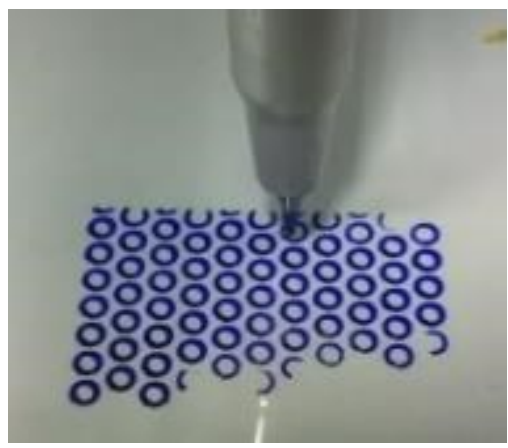

Figura 4: Gravação dos círculos usados para medir a deformação.

A medição dos círculos foi executada em uma máquina de medição ótica marca Class, modelo 3020 VM, com zoom de 36 vezes.

\section{RESULTADOS E DISCUSSÃO}

A fim de que fosse possível avaliar o comportamento do material previamente, foi feito o ensaio de tração com base na norma ASTM D638-97 (amostra tipo I) e gravado pequenos círculos de $3 \mathrm{~mm}$ de diâmetro em uma das faces dos corpos de prova, conforme mostra a Figura 5(a); 5(b) e 5(c). À medida que a peça sofre 
tração, seja durante o teste ou na conformação, esses círculos se deformam, Figura 5(a) e 5(b), tornado a avaliação da deformação possível.

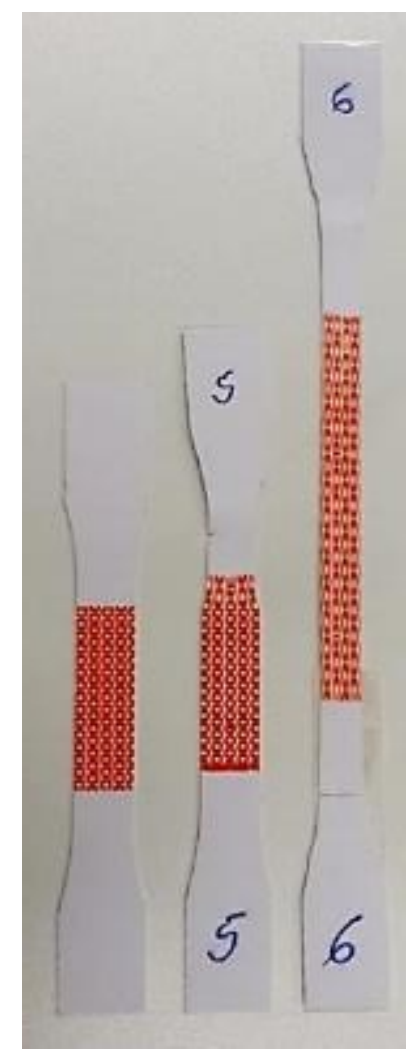

(a) (b) (c)

Figura 5: Amostras dos ensaios de tração $n^{\circ} 5$ e 6. (a) antes do ensaio. (b) ensaio a $25^{\circ} \mathrm{C}$. (c) ensaio a $42^{\circ} \mathrm{C}$.

Foram executados 5 ensaios válidos com temperatura ambiente e outros 5 com acréscimo de $17^{\circ} \mathrm{C}$ temperatura, através de uma fonte de calor luminosa, como já foi mostrado. O gráfico da Figura 5 mostra os resultados para dois testes, obtidos como a curva média entre os ensaios válidos. O material antes do ensaio, teste a temperatura de $25{ }^{\circ} \mathrm{C}$, e temperatura média de $45{ }^{\circ} \mathrm{C}$ são mostrados na Figura 5 (a), (b) e (c) respectivamente. É possível notar que há uma grande diferença na deformação final do material. À temperatura de $25^{\circ} \mathrm{C}$ o material se deformou apenas $20,5 \mathrm{~mm}$ até romper e praticamente manteve a mesma espessura de 0,6 $\mathrm{mm}$. Aplicando uma temperatura de $42^{\circ} \mathrm{C}$, o material se deformou até o comprimento final de $113,8 \mathrm{~mm}$ e teve uma espessura final de $0,40 \mathrm{~mm}$, o que representa $33 \%$ de redução.

Isso mostra que o material, ao ser submetido a uma fonte de calor, ou seja, aquecido, é capaz de gerar um aumento de tamanho longitudinal de aproximadamente $75 \%$, que corresponde a $3 / 4$ do tamanho original com apenas $33 \%$ de redução na espessura.

A Figura 6 mostra o Gráfico que foi gerado nesse ensaio de tração, onde é possível observar que sob temperatura, a força de tração é menor, mas gera-se maior deformação até a ruptura. No início do ensaio, há um pico de força nos dois testes, isso se deve ao alinhamento das moléculas do polímero que ficam no formato disperso no interior do material. 


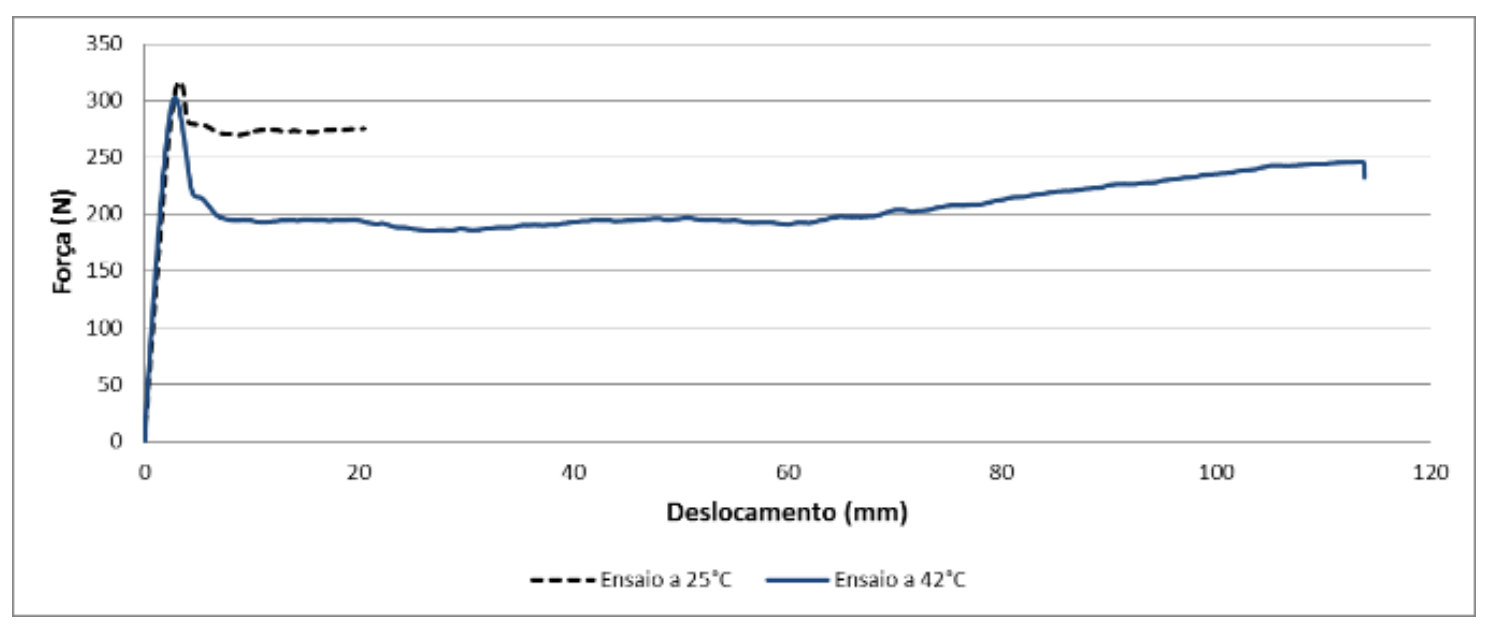

Figura 6: Gráfico de força por deslocamento gerado no ensaio de tração do $\mathrm{PVC}$ a $25^{\circ} \mathrm{C}$ e a $42^{\circ} \mathrm{C}$.

Para validar e testar a metodologia de medição dos círculos impressos na chapa, essa foi feita na chapa submetida aos ensaios de tração. A Figura 7 mostra o corpo de prova ainda não submetido ao ensaio. As das deformações ocorridas foram calculadas através da equação 1 .

$$
\varphi=\ln \frac{l}{d}
$$

em que $d$ é o diâmetro inicial do círculo, $l$ é o eixo da elipse após deformado (pode ser tanto o eixo maior como o menor).

Após a chapa ser tracionada, foi feita a medição de vários corpos de prova com gravação de círculos de $3 \mathrm{~mm}$ de diâmetro. Na Figura 8, a conformação deu-se a $25^{\circ} \mathrm{C}$, onde foi medida a deformação apenas em um ponto do corpo de prova conforme demonstra-se na imagem. Não houve espaço suficiente para se ter uma leitura de outro círculo deformado. A deformação maior, que corresponde ao maior valor da elipse medida foi de $64 \%$. É possível observar também que o corpo de prova não deformou de maneira uniforme, ou seja, só uma parte se deformou, o resto ficou praticamente intacto. Essa observação se manteve em todas as amostras testadas. Isso ocorre porque para polímeros vítreos, como é o caso do PVC, a uma temperatura muito abaixo da temperatura de transição vítrea, onde o polímero se comporta com duro e quebradiço, a probabilidade de se promover alinhamento das cadeias carbônicas é igualmente baixa, e isso gera uma deformação não uniforme no material.

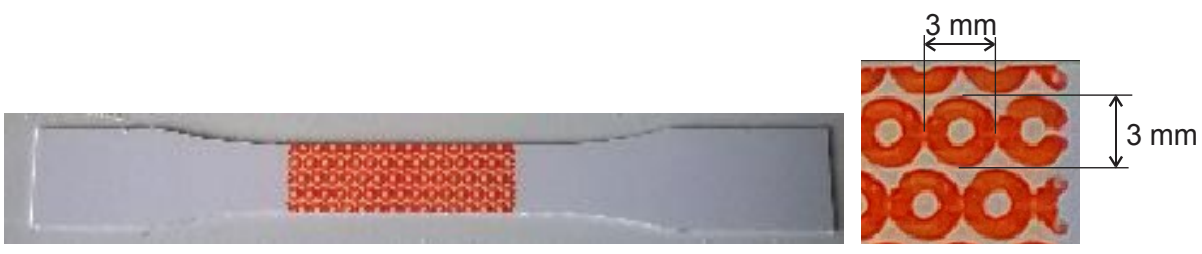

Figura 7: Corpo de prova não ensaiado com o formato do círculo impresso e suas dimensões. 


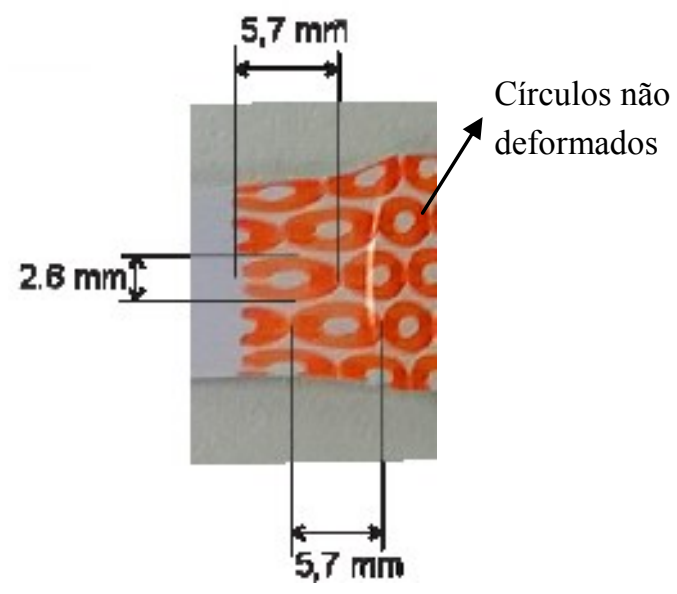

Figura 8: Corpo de prova ensaiado a temperatura de $25^{\circ} \mathrm{C}$.

No ensaio feito a temperatura de $42^{\circ} \mathrm{C}$, o corpo de prova obteve uma deformação homogênea em toda a extensão do ensaio até o rompimento. Neste ensaio, conforme demonstra a Figura 9, a deformação deu-se de maneira uniforme, com uma variação mínima entre as medições. Isto mostra a moldabilidade do material, onde seu tamanho duplica quando submetido a uma fonte de calor constante. A deformação maior ficou em 6,6 mm para as elipses medidas, o que demostra que a aplicação de temperatura aumentou as deformações do processo.

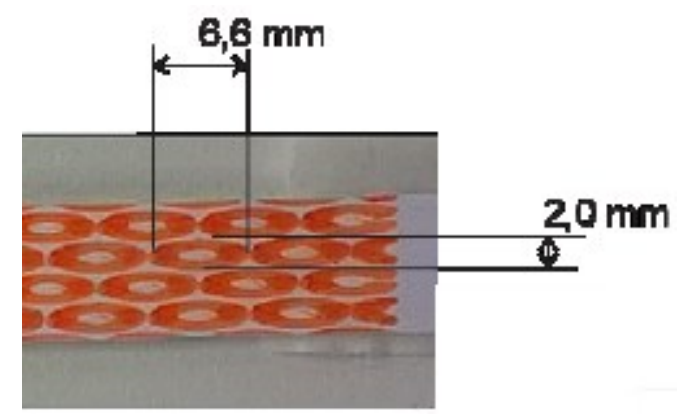

Figura 9: Corpo de prova ensaiado a temperatura de $42^{\circ} \mathrm{C}$.

Após os ensaios de tração, foi possível testar o material com as ferramentas de 1,5 mm, $3 \mathrm{~mm}$ e $6 \mathrm{~mm}$ de diâmetros, conforme descrito anteriormente. $\mathrm{O}$ teste foi dividido em 2 etapas, a primeira etapa foi executada em temperatura ambiente e a segunda parte foi executada com uma fonte de calor.

Alguns parâmetros foram mantidos, com a lubrificação, considerado indispensável em qualquer tipo de conformação e a temperatura ambiente, em torno de $25^{\circ} \mathrm{C}$.

O parâmetro descrito anteriormente, trajetória do punção, foi-se revelando de suma importância, pois foi observado que a cada etapa deveria ser revertido o sentido de estampagem incremental, de horário para anti-horário e vice versa, diminuindo o efeito de torção do material. A velocidade de avanço também foi mantida constante em $180 \mathrm{~mm} / \mathrm{min}$.

Após os testes, a chapa é planificada para ser submetida às medições dos círculos. Na Figura 10(a) e 10(b), foram determinados 8 pontos para medição das deformações, 4 pontos na linha horizontal, e 4 pontos na linha vertical, denominados (h) e (v), horizontal e vertical respectivamente. Dessas medições, foi escolhida a medida de maior valor observada nas linhas horizontal e vertical e os valores inseridos na Tabela 1. Assim foi possível analisar o efeito das maiores deformações em cada etapa. 


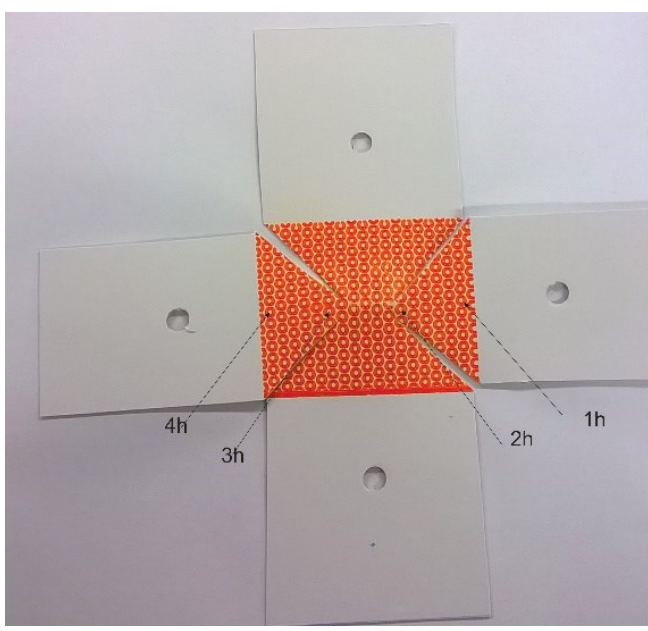

(a)

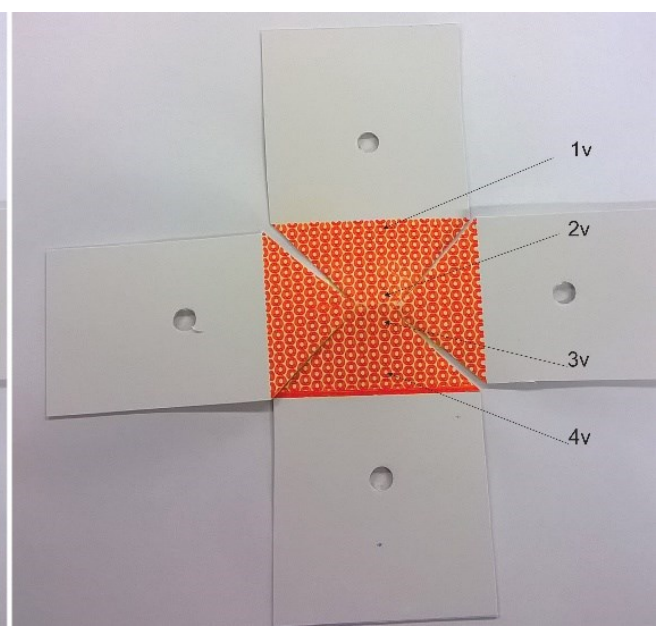

(b)

Figura 10: Peças conformadas e planificadas com identificação dos pontos. (a) horizontal; (b) vertical.

Conforme é possível observar pelos dados da Tabela 1, com as medições sem adição de calor, a etapa 1 começa gerando maiores deformações para as ferramentas de 1,5 e $6 \mathrm{~mm}$ de diâmetro com relação as medições com adição de calor. Para a ferramenta de $6 \mathrm{~mm}$ de diâmetro, sem a aplicação de calor, as deformações na última etapa foram maiores em relação a mesma etapa com adição de calor, esse efeito foi observado nas linhas horizontal e vertical.

Tabela 1: Medição da deformações máximas.

\begin{tabular}{|c|c|c|c|c|c|c|c|c|c|c|c|c|}
\hline \multirow[b]{3}{*}{$\Phi$ Punção (mm) } & \multicolumn{6}{|c|}{ HORIZONTAL } & \multicolumn{6}{|c|}{ VERTICAL } \\
\hline & \multicolumn{3}{|c|}{ SEM CALOR } & \multicolumn{3}{|c|}{ COM CALOR } & \multicolumn{3}{|c|}{ SEM CALOR } & \multicolumn{3}{|c|}{ COM CALOR } \\
\hline & 1,50 & 3,00 & 6,00 & 1,50 & 3,00 & 6,00 & 1,50 & 3,00 & 6,00 & 1,50 & 3,00 & 6,00 \\
\hline Etapa 1 & 0,19 & 0,16 & 0,13 & 0,11 & 0,04 & 0,10 & 0,14 & 0,09 & 0,07 & 0,09 & 0,01 & 0,11 \\
\hline Etapa 2 & 0,28 & 0,26 & 0,30 & 0,25 & 0,33 & 0,32 & 0,29 & 0,23 & 0,25 & 0,18 & 0,25 & 0,27 \\
\hline Etapa 3 & 0,45 & - & 0,54 & 0,41 & 0,53 & 0,46 & 0,42 & - & 0,58 & 0,33 & 0,40 & 0,33 \\
\hline
\end{tabular}

Nas leituras horizontal e vertical observou-se semelhança de valores medidos em todas as etapas, nos testes sem e com adição de calor. A etapa 3, com todos os punções, foi a última porque a etapa seguinte apresentou rompimento, sendo que a etapa 4 não foi realizada, ou seja, o objetivo era se obter as 4 etapas, mas se houvesse início de rompimento da chapa em uma das etapas, a mesma chapa não poderia ser estampada em uma etapa seguinte, sendo interrompido o teste e analisadas as deformações geradas. No entanto, o momento da ruptura se deu em regiões diferentes. Para as ferramentas de 3 e $6 \mathrm{~mm}$ de diâmetro a ruptura se deu na parte inferior da geometria testada, já a ferramenta de $1,5 \mathrm{~mm}$ apresentou ruptura logo no início da etapa 4 . Esse efeito foi similar nos testes com e sem calor. Desse modo, constatou-se que a ferramenta de 1,5 mm teve desempenho inferior em relação as outras.

Ao se comparar a ferramenta de $6 \mathrm{~mm}$ com e sem calor, é possível observar que com a aplicação do calor chegou-se a mesma geometria com deformações menores, ou seja, a aplicação do calor distribuiu melhor as deformações. Os dados obtidos com punção de $3 \mathrm{~mm}$ sem calor chegaram a mesma geometria com deformações ainda menores, ou seja, houve rompimento na terceira etapa, isso difere dos resultados da mesma ferramenta com aplicação do calor. Dessa forma a ferramenta de $3 \mathrm{~mm}$ sem calor destoou dos resultados, fazendo com que esses dados não façam parte da análise global dos experimentos, seriam necessários mais testes para se verificar o porquê dos dados terem sido incoerentes. Isso é um importante resultado, pois se a distribuição das deformações são mais homogêneas, há uma menor probabilidade de geração de uma falha por ruptura, visto que esse tipo de falha é gerado pelo acumulo de deformações em algum ponto localizado da chapa que no estágio seguinte gera um início de falha e que se propaga até o colapso da peça.

Como foi observado anteriormente, com a ferramenta de $6 \mathrm{~mm}$, obteve-se os melhores resultados. Por isso, foram plotadas as distribuições das deformações nas linhas horizontal e vertical. Analisando os gráficos 
da Figura 11 e 12, é possível notar que houve homogeneização das deformações ao longo das linhas nos testes com calor, ou seja, se chegou a mesma geometria com deformações menores.

Isso é um importante resultado, pois se a distribuição das deformações são mais homogêneas, há uma menor probabilidade de geração de uma falha por ruptura, visto que esse tipo de falha é gerado pelo acumulo de deformações em algum ponto localizado da chapa que no estágio seguinte gera um início de falha que se propaga até o colapso da peça e que, por conseguinte, inutiliza a geração do protótipo.
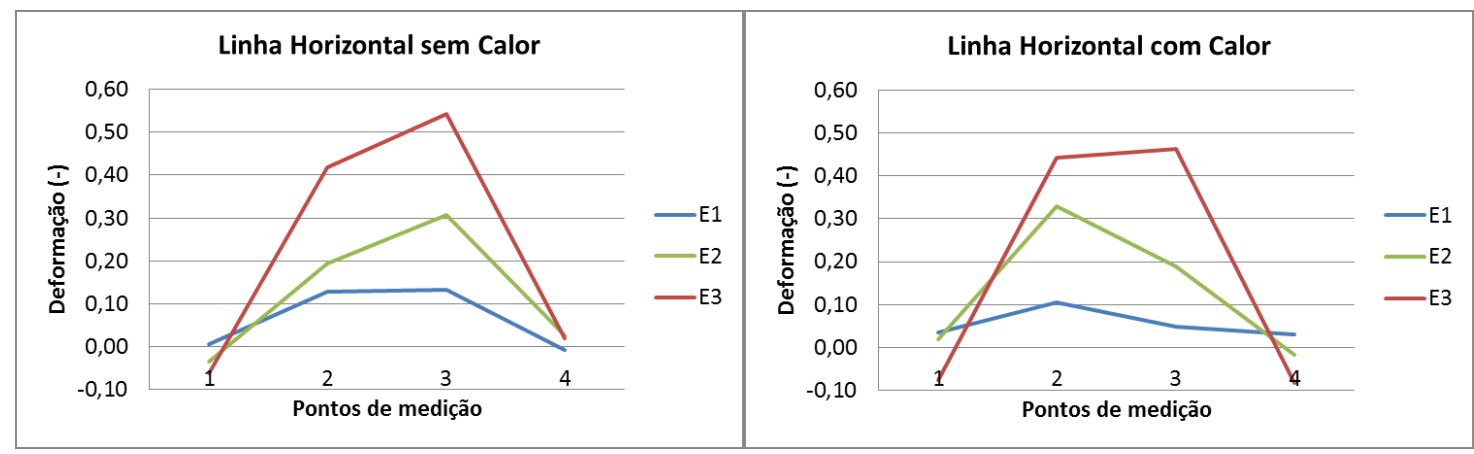

Figura 11: Gráfico de medição da deformação para punção de $6 \mathrm{~mm}$. Linha horizontal.

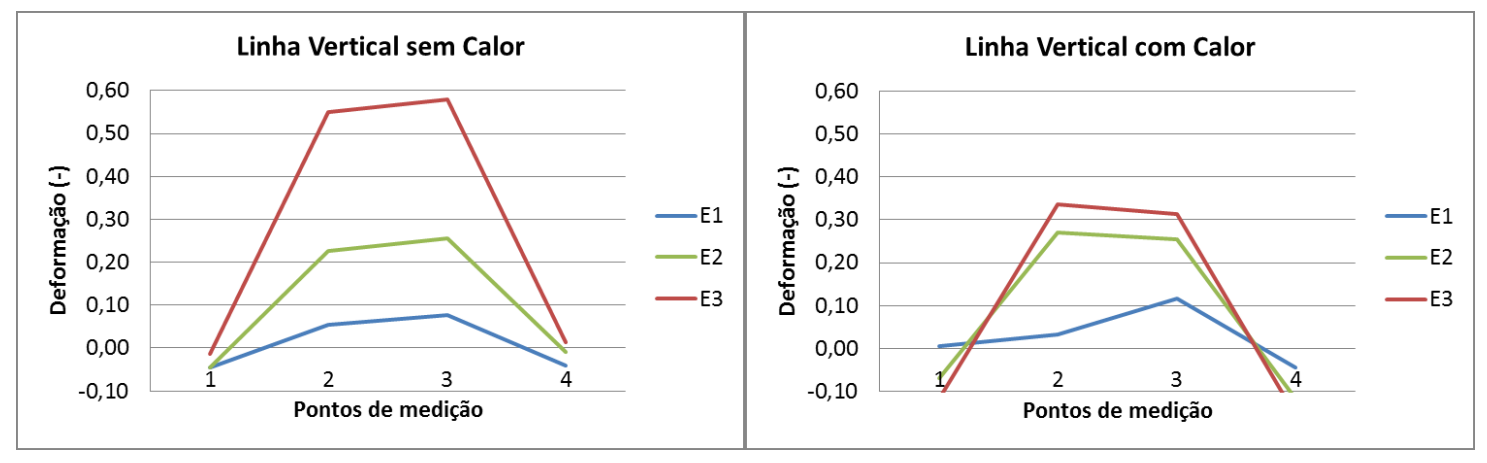

Figura 12: Gráfico de medição da deformação para punção de $6 \mathrm{~mm}$. Linha vertical.

\section{CONCLUSÕES}

O processo de EI é bastante promissor em relação à forma do produto a ser gerada, o que precisa ser feito é apenas o ajuste de parâmetros de processo como a temperatura de trabalho, o diâmetro do punção, espessura do material e a trajetória da ferramenta. Porém, protótipos com ângulo de parede inicial muito alto são de difícil obtenção, pois esses ângulos geram acúmulo de deformação que acabam gerando falhas logo no início do processo.

No que diz respeito aos parâmetros de controle do processo de EI, esses tem uma contribuição importante. Já é sabido que o passe vertical tem papel fundamental para o sucesso da obtenção de um protótipo assim como a velocidade desses passes. Isso não foi analisado nesse trabalho pois outros parâmetros ainda não tinham sido testados, como a temperatura de trabalho da chapa. Como foi visto, a temperatura apresenta um papel importante para distribuir as deformações. No entanto, é importante ressaltar que essa temperatura de trabalho deve ser controlada, uma vez que, em se tratando de polímeros, o limite é bastante baixo. A Tg (temperatura de transição vítrea) para o $\mathrm{PCV}$, por exemplo, é de $80^{\circ} \mathrm{C}$ e isso mostra que uma variação não controlada nessa temperatura pode fazer com que o processo não seja obtido.

Em relação a outros parâmetros, como a lubrificação da chapa, foi observado que é indispensável, pois sem a aplicação de lubrificante, a ferramenta de trabalho acaba por aquecer localmente a chapa que adere a ferramenta e isso, no final do processo, promove uma remoção e aglutinação de material. Dessa forma, não há como obter um protótipo sem a aplicação dessa lubrificação.

Por fim, em relação ao diâmetro da ferramenta de trabalho, foi possível observar que quanto maior o diâmetro da mesma, melhores são os resultados. Isso indica que a área de contato entre a chapa e a ferramenta tem um papel decisivo na obtenção do protótipo e não haverá aquecimento localizado pois o lubrificante 
controla os níveis de atrito que promovem esse aquecimento. No entanto, mais testes são necessários para confirmar essa teoria.

\section{AGRADECIMENTOS}

Os autores agradecem ao Centro Universitário Ritter dos Reis pelo apoio na elaboração desse estudo.

\section{BIBLIOGRAFIA}

[1] MARTINS, P.A.F., KWIATKOWSKI, L., FRANZEN, V., et al., "Single point incremental forming of polymers". CIRP Annals - Manufacturing Technology, v. 58, p. 229-232, 2009.

[2] FRANZEN, V., KWIATKOWSKI, L., MARTINS, P.A.F., et al., "Single point incremental forming of PVC", Journal Of Materials Processing Technology, v. 209, pp. 462-469, 2009.

[3] SILVA, M.B., ALVES, L. M., MARTINS, P. A. F. "Single point incremental forming of PVC: Experimental findings and theoretical interpretation", European Journal of Mechanics A/Solids, v. 29, pp. 557-566, 2010.

[4] ALKAS YONAN, S., SOYARSLAN, C., HAUPT, P., et al., "A simple finite strain non-linear viscoplastic model for thermoplastics and its application to the simulation of incremental cold forming of polyvinylchloride (PVC)", International Journal of Mechanical Sciences, v. 66, pp 192-201, 2013.

[5] DAVARPANAH M. A., MIRKOUEI A., YU X., MALHOTRA R., et al., "Effects of incremental depth and tool rotation on failure modes and microstructural properties in Single Point Incremental Forming of polymers", Journal of Materials Processing Technology, v. 222, p. 287-300, 2015.

[6] BAGUDANCH, I., GARCIA-ROMEU, M.L., CENTENO, G., et al., "Forming force and temperature effects on single point incremental forming of polyvinylchloride", Journal of Materials Processing Technology, v. 219, pp. 221-229, 2015.

[7] BAGUDANCH I., MARTÍNEZ-ROMERO O., ELÍAS-ZÚÑIGA A., et al., "Identifying Polymeric Constitutive Equations for Incremental Sheet Forming Modelling”, Procedia Engineering, v. 81, p. 2292-2297, 2014.

[8] BAGUDANCH I., GARCIA-ROMEU M.L., SABATER M., "Incremental forming of polymers: process parameters selection from the perspective of electric energy consumption and cost", Journal of Cleaner Production, v. 112, p. 1013-1024, 2016.

[9] HUSSAIN G., GAO L., DAR N.U., "An experimental study on some formability evaluation methods in negative incremental forming", Journal of Materials Processing Technology, v. 186, p. 45-53, 2007.

[10] HUSSAIN G., DAR N.U., GAO L., CHEN M.H., "A comparative study on the forming limits of an aluminum sheet-metal in negative incremental forming", Journal of Materials Processing Technology, v. 187-188, p. 94-98, 2007

[11] CASTELAN, J., Estampagem incremental do titânio comercialmente puro para aplicação em implante craniano, Tese de D.Sc., UFRGS, Porto Alegre, RS, 2010. 